\title{
Projeto Relesa-Elanem: uma Nova Proposta Metodológica de Índices e Indicadores para Avaliação da Qualidade Ambiental
}

\author{
Cendrero, A. ${ }^{(1)}$; Frances, E. ${ }^{(1)}$; Latrubesse, E. M. ${ }^{(2)}$; Prado, R. ${ }^{(2)}$; Fabbri, A. ${ }^{(3)}$; Panizza, M. ${ }^{(4)}$; \\ Cantu, M. P. ${ }^{(5)}$; Hurtado, M. ${ }^{(6)}$; Gimenez, J. E. ${ }^{(6)}$; Martinez, O. ${ }^{(6)}$; Cabral, M. ${ }^{(6)}$; Tecchi, R. A. \\ ${ }^{(7)}$; Hamity,V. ${ }^{(7)}$;Ferman, J. L. ${ }^{(8)}$; Quintana, C. ${ }^{(9)}$; Ceccioni, A. ${ }^{(10)}$, Recatalá, L. . ${ }^{(11)}$; Bayer, M. ${ }^{(2)}$;
} Aquino, S. ${ }^{(2)}$.

1 Universidad de Cantabria Facultad de Ciencias Santander-Espanha

2 Universidade Federal de Goiás Instituto de Estudos Sócio-Ambientais Goiânia Goiás Brasil. Campus II-Samambaia, C. P. 131, CEP: 74001-970, fone: (62) 521-1184, e-mail: latrubes@iesa.ufg.br e pradoroberto@bol.com.br

3 International Institute for Aerospace Survey and Earth Sciences (ITC) Geological Survey Division Enschede Holanda. 4 Università Degli Studi di Modena e Reggio Emilia Dipto. di Scienze della Tierra Módena Itália.

5 Universidad Nacional de Rio Cuarto Depto. De Geologia Rio Cuarto Argentina.

6 Universidad Nacional de La Plata Facultad de Ciencias Naturales La Plata Argentina. 7 Universidad Nacional de Jujuy Jujuy Argentina.

8 Universidad Autonoma de Baja California Facultad de Ciencias Marinas- Ensenada México.

9 Universidad Central de Las Villas Facultad de Ingenieria Mecânica Santa Clara Cuba.

10 Universidad de Concepcion Dept. Ciencias de La Tierra Concepcion - Chile.

11 Universidad de Valencia CIDE Valencia-Espanha

Recebido 04 de abril 2001; revisado 02 de março 2002; aceito 22 de agosto 2002

\begin{abstract}
RESUMO
O objetivo principal do projeto RELESA/ELANEM foi elaborar uma nova proposta metodológica para a obtenção de índices e indicadores quantitativos de avaliação da qualidade ambiental que seja aplicável a diferentes regiões e ofereça a possibilidade de obter resultados quantitativamente comparáveis. A proposta remete em testar um procedimento capaz de medir a qualidade ambiental e possíveis relações estabelecidas com as pressões derivadas de ações humanas, assim como o nível de resposta da sociedade para mudanças na condição do ambiente, objetivando a sustentabilidade dos recursos naturais. A espacialização das informações dá-se através da identificação, mapeamento e análise de Unidades Ambientais Integradas, delimitadas com atributos distintos, isto é, de acordo com as formas de uso e ocupação de cada ambiente. É neste contexto que a componente geomorfológica assume importância fundamental na delimitação destas unidades.
\end{abstract}

Palavras chave: qualidade ambiental, sustentabilidade, Geomorfologia.

\begin{abstract}
The main objective of the RELESA/ELANEM project was to design and test a procedure for measuring environmental quality and to establishing possible relationships between the pressures derived from human actions and the level of societal response to changes in the condition of the environment. The method should enable meaningful spatial and temporal comparisons, so that it can be applied for both the assesment of present condition of the environment and the monitoring of environmental changes. A set of measurable indicators and index were developed. The index and indicators can be used for assessing the quality of different environmental components. The spatial representation of data and results is realized using maps of environmental unites. Environmental units are delimited using several approaches but in all of them Geomorphology play a fundamental role.
\end{abstract}

Keywords: enviromental quality, sustentability, Geomorphology.

\section{Introdução}

O RELESA / ELANEM (ERBIC 18CT980290) é um projeto destinado à aplicação de indicadores quantitativos e índices de avaliação de qualidade ambiental. Este projeto é financiado pelo Programa INCO-DC (International Cooperation with Developing Countries) da União Européia.

A Conferência das Nações Unidas de Desenvolvimento e Meio Ambiente realizada em
1992 marcou um ponto decisivo quanto as preocu-pações ambientais. Os resultados daquela conferên-cia, especialmente as convenções internacionais ado-taram metas e ações contidas na agenda 21 apontan-do para a necessidade de desenvolver e aplicar méto-dos que determinem o estado do ambiente e monito-rar suas mudanças em níveis locais, regionais, nacio-nais e globais. Determinar essas mudanças permitirá avaliar as dimensões dos diversos problemas ambi-entais e 
conduzir os resultados para aplicação de convenções internacionais, programas de ação e políticas nacionais. O conceito de pressão, estado e resposta (OECD, 1993, 1994) ou as forças motrizes mais abrangentes de pressão, estado, impacto e resposta (Mortensen, 1997; Jimenez-Beltran, 2000) são particularmente úteis para estes propósitos.

Uma das desvantagens de qualquer conjunto de indicadores é que eles fornecem informações sobre as condições e mudanças de uma série de parâmetros ambientais muito diferentes. O significado dessas mudanças, do ponto de vista da qualidade ambiental global, podem não estar claras até mesmo para especialistas, e menos ainda para políticos, planejadores e a população de forma geral. Surge, então, a necessidade em definir índices que combinem vários indicadores, objetivando obter informações integradas sobre certos estados ambientais (Scope, 1995).

O Índice de Desenvolvimento Humano (IDH) do UNDP (UNDP, 1996) representa um bom exemplo de desenvolvimento de índices integrados que podem auxiliar na medição de qualidades complexas. Tais procedimentos contribuem na análise e na evolução do ambiente em uma perspectiva mais ampla, que neste caso refere-se à sustentabilidade do meio ambiente.
O objetivo da pesquisa visa estabelecer um procedimento de medição e avaliação da qualidade ambiental, que possibilite fazer comparações no tempo e no espaço, servindo de base à tomada de de-cisões sobre a gestão do território, com o fim de al-cançar um uso mais sustentável do mesmo e de seus recursos. Para isto, fez-se necessário adotar métodos que definem critérios objetivos e quantificáveis.

Os estudos são conduzidos segundo a sub-divisão hierárquica do território baseada em combi-nações de aspectos físico-naturais e político admi-nistrativos (Cendrero et. al., 1992, 1998). Estes pro-cedimentos abrangem uma proposta integrada de avaliação que considera o desenvolvimento sustenta-vel e o bem estar das populações.

O projeto conta com diversos parceiros dis-tribuídos em oito países da Europa e América Latina onde as pesquisas estão sendo desenvolvidas. São eles: Espanha, Holanda, Itália, México, Cuba, Brasil, Argentina e Chile. As pesquisas em desenvolvimen-to nestes oito países estão distribuídas em dez áreas de estudo as quais apresentam características natura-is e sócio-econômicas bastante heterogêneas. A tabela 1, traz, de forma sintética, os parceiros, áreas de pesquisa e temas desenvolvidos:

Tabela 1 Instituições de pesquisa envolvidas, temas e áreas de estudo.

\begin{tabular}{|c|c|c|}
\hline PARCEIROS & TÓPICOS T & ÁREA DE ESTUDO \\
\hline $\begin{array}{l}\text { Universidad de Cantabria } \\
\text { UCAN (Espanha) }\end{array}$ & 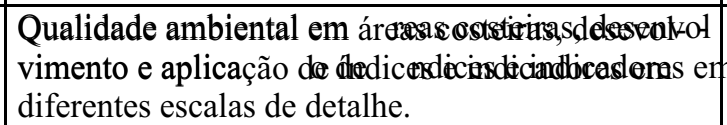 & Norte da Espanha \\
\hline ITC (Holanda) & 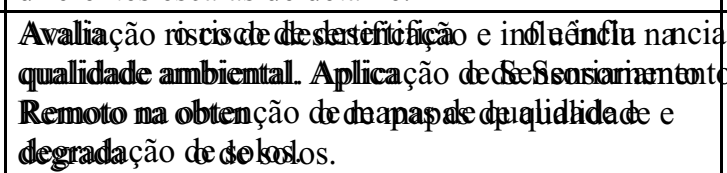 & $\begin{array}{l}\text { Aambiente Semi-árido rid } \phi \\
\text { pmediterrâne } \phi \$ 8 \text { dedetste } \\
\text { da Espanha) }\end{array}$ \\
\hline 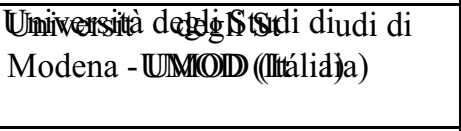 & 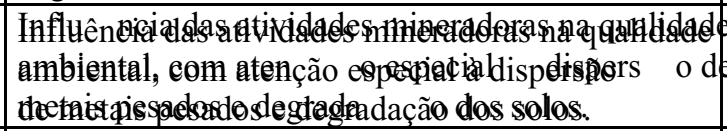 & $\begin{array}{l}\text { Ambiente alpino (Noro - } \\
\text { eeste da Itáliłiła) }\end{array}$ \\
\hline $\begin{array}{l}\text { Universidad AutónnmaaddeBBjeja } \\
\text { Califonia UABAB(M(Axicox) }\end{array}$ & 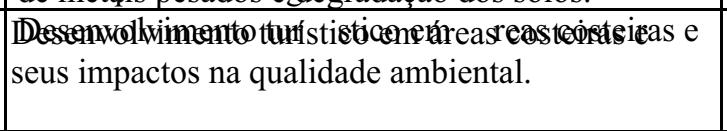 & $\begin{array}{l}\text { Ambiente costeiro semi- } \\
\text { árido (Baja Califórniraia, } \\
\text { Méxicieø) }\end{array}$ \\
\hline $\begin{array}{l}\text { Universidad Central de Las } \\
\text { Villas - UCLV (Cuba) }\end{array}$ & 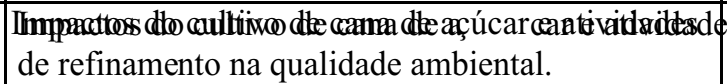 & Suba Central \\
\hline $\begin{array}{l}\text { Universidade Federal de Goiás s } \\
\text { UFG (Brasil) }\end{array}$ & 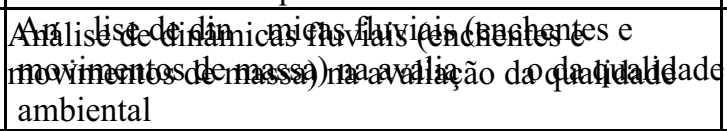 & 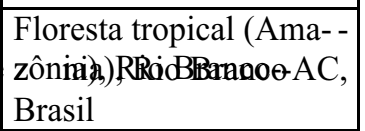 \\
\hline $\begin{array}{l}\text { Universidad Nac ional de Rio } \\
\text { Cuarto - UNRC, incluindo Uni - } \\
\text { versidad Nacional de La Plata - } \\
\text { UNLP e Universidad Nacional } \\
\text { de Jujuy - UNJU (Argentina) }\end{array}$ & 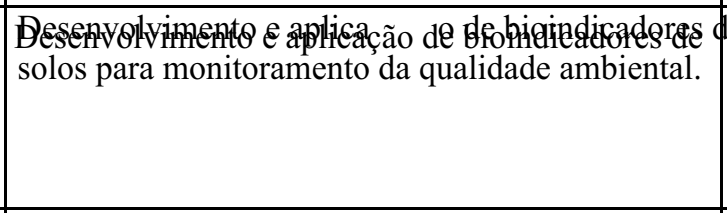 & $\begin{array}{l}\text { Região đmidhaidøsdos } \\
\text { Pampas, Arg entina Cen- } \\
\text { tral e zona dos altos } \\
\text { Andes (Argentina) }\end{array}$ \\
\hline Umiversidad de Comcepciónn- - & 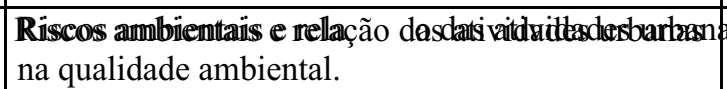 & $\begin{array}{l}\text { Costa úmindidetemperera - } \\
\text { da, Chile central (Chile) }\end{array}$ \\
\hline
\end{tabular}


A proposta do RELESA-ELANEM pretende testar uma metodologia capaz de medir a qualidade ambiental e as relações estabelecidas com as pressões derivadas de ações humanas e seu nível de resposta diante das modificações no ambiente natural.

Coube às distintas equipes envolvidas desenvolver uma lista de indicadores mensuráveis que permitem serem usados para avaliar a qualidade dos diferentes componentes ambientais existentes segundo a particularidade de cada ambiente. O que levou a obtenção de índices integrados significantes para expressar aspectos diferenciados de qualidade ambiental e permitir comparações entre os diferentes tipos de ambientes.

\section{Bases Geomorfológicas como Suporte à Integração e Espacialização de Dados}

A elaboração de um mapa geomorfológico tem por objetivo reproduzir em planta a realidade geomorfológica de determinada área. Temos neste produto, uma base cartográfica com uma série de informações que servem à utilidades que superam sua finalidade inicial. Do ponto de vista da Geomorfologia, o relevo como base física de sustentação converte-se em bem passível de apropriação servindo de suporte às atividades humanas, e, conseqüentemente, como capacidade de suporte ambiental.

A análise geomorfológica permite avançar na aplicação metodológica aplicando técnicas quantitativas, isto é, fazendo uso de cálculos matemáticos que quantifiquem os resultados. Com resultados pragmáticos e as possibilidades de aplicação direta dos mesmos, tais técnicas constituem-se como elemento de apoio à tomada de decisões que neste caso visam promover a qualidade ambiental.

A obtenção dos mapas base reflete, de forma descritiva, a constituição da área de estudo, expressa por meio de Unidades Ambientais Integra-das. Estas unidades definem-se cartograficamente sobre a base de critérios relativos à:

!Geomorfologia;

!Vegetação Uso e ocupação da terra.

A descrição das unidades leva em consideração outras características, tais como solo, fauna, aspectos antropogênicos relevantes e riscos ambientais significativos pautados no contexto geomorfológico e demais variáveis ambientais do ponto de vista natural e/ou acelerado quando intensificados pela ocupação humana.

Destaca-se, ainda, que os estudos desta natureza tem contado cada vez mais com o suporte operacional dos Sistemas de Informação Geográficas SIG's. Sua aplicabilidade tem revelado apoio fundamental na abordagem pragmática que requerem estes estudos, sobretudo na espacialização de dados.

\section{Principais Bases da Estrutura Metodológica}

O método consiste em estabelecer uma proposta comum e um número mínimo de índices e indicadores que possibilite fazer comparações entre as dezáreas de estudo testando a validade do mesmo.

As análises são feitas baseadas na identificação e mapeamento de Unidades Ambientais Integradas (físico-naturais e político-administrativa).

Na identificação e combinação dos indicadores da qualidade ambiental para obtenção de índi-ces numéricos, foram consideradas algumas particu-laridades:

! Critérios de qualidade ambiental;

!Tipos de indicadores e seu significado;

! Componentes ambientais ou partes deles que possam ser representados por meio de indicadores específicos;

! Tipos de unidades de espaço os quais a avali-ação será aplicada.

Os indicadores foram combinados para ob-ter índices integrados. Partindo dos componentes e características ambientais, individualizou-se dois sis-temas que simplificam a avaliação: físico-naturais e político-administrativa.

A estrutura deste banco de dados integrado permite aos diversos parceiros em suas respectivas áreas, identificar as características e influências des-tes dois sistemas, aplicar indicadores para avaliar estas unidades e quantificá-los.

A estrutura conceitual da organização do projeto, de acordo com a figura 1, ilustra o foco de interesse dos grupos envolvidos, a interrelação entre os mesmos e as atividades desenvolvidas.

Dos fatores físico-naturais obtêm-se os índi-ces de qualidade ambiental e seu uso, além de apon-tar sua potencialidade para desenvolvimento de ati-vidades de forma sustentável. Os fatores políticos-administrativos resultam em índices que avaliam o estado dos recursos, riscos, ocupação, pressão e res-postas. A integração dos diversos índices é o ponto de convergência que revela os resultados já alcança-dos, passando assim pelo mapeamento (espacializa-ção das informações) e elaboração do banco de da-dos. De forma mais abrangente a avaliação e identi-ficação dos aspectos de pressão, estado e a relação de respostas, vem conseqüentemente subsidiar as propostas de desenvolvimento sustentável que se pretende. Esta estrutura está organizada sob a forma de um modelo esquemático que pode ser visualizado na figura 2 .

A qualidade ambiental é considerada sob duas perspectivas: ecocêntrico e antropocêntrico. Do ponto de vista ecocêntrico, a qualidade ambiental re-laciona-se diretamente com o grau de naturalidade, quanto mais preservada a natureza primitiva de uma área, maiores são suas qualidades. Na visão antropo-cêntrica considera-se a qualidade ambiental como reflexo das funções do ambiente para os seres hu-manos (Scope, 1995), ou seja, é a relação entre três funções fundamentais que desempenha o meio am-biente: fonte de recursos, sumidouro de resíduos e suporte de atividades/provedor de serviços, além de outra função secundaria que diz respeito aos as-pectos sócio econômicos. As três primeiras funções especificamente, devem ser consideradas tendo em conta a idéia de sustentabilidade. 


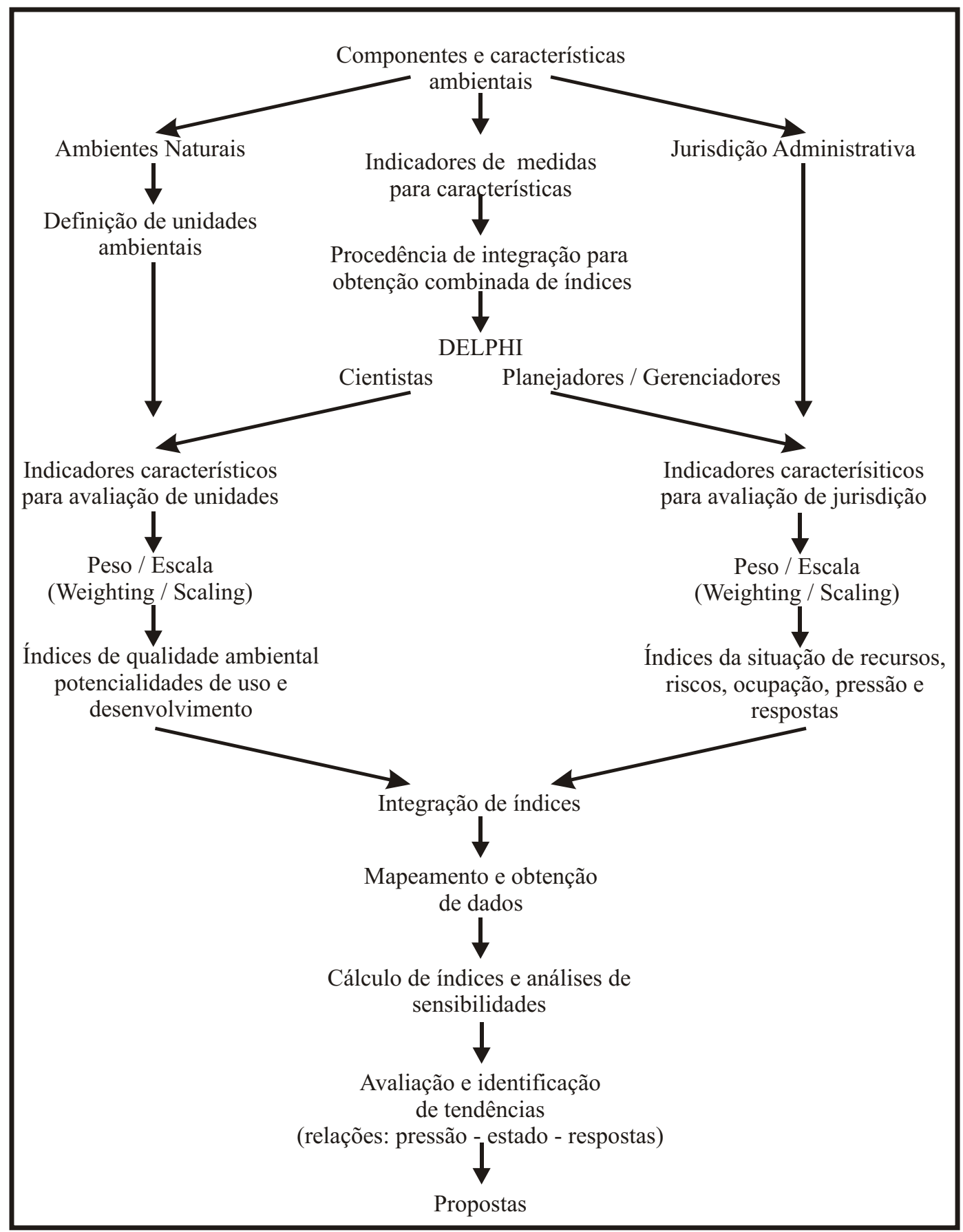

Figura 1: Organograma metodólogico I

Utiliza-se também como indicador o IDH como caráter geral em todas as zonas segundo a proposta das Nações Unidas. Adicionalmente, deve-se desenvolver e aplicar outros índices do tipo sócioeconômico para cada área, já que permitem fazer comparações significativas com os índices ambientais previamente estabelecidos.

Os índices são calculados aplicando procedimentos de weigthing/rating, transformando os valores dos indicadores em escalas de 0-1 e com a soma de pesos igual a 1 , de modo que todos os índices variam entre 0 e 1 para facilitar as comparações.

Indicadores que possam ser usados para medir naturalidades ou funções ambientais, podem ser de diferentes tipos. Foram amplamente aceitos na estrutura metodológica indicadores para ob-tenção de índices de P-E-R (Pressão, Estado e Resposta). Nesta estrutura, trabalha-se com uma relação de causa-efeito entre pressões do ambiente e seus reflexos que chegam em forma de respostas. Em-bora em muitos casos não seja possível conhecer os processos exatos pelos quais as relações são estabe-lecidas, indicadores de P-E$\mathrm{R}$, podem determinar recursos aconselháveis de ações. 


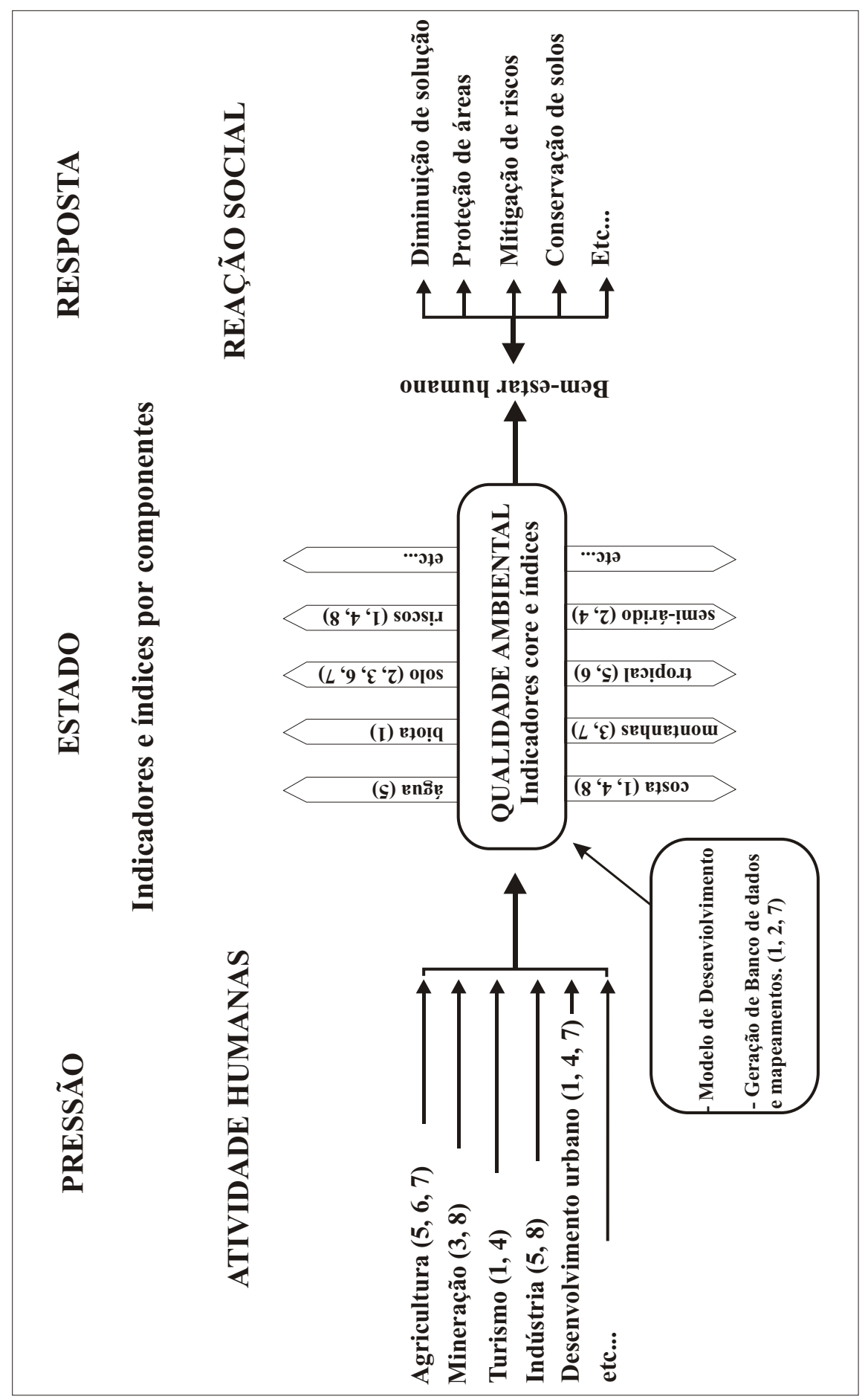

Figura 2: Organograma metodológico II.

Foram selecionados inicialmente, cerca de setenta indicadores de qualidade ambiental. O procedimento para o cálculo destes índices são:

1 - Foram normalizados indicadores usando uma escala que varia de 0 a 1 .

$\mathrm{V}=(\mathrm{IM}-\mathrm{IMIN}) /(\mathrm{IMAX}-\mathrm{IMIN})$;

onde: $\mathrm{V}=$ Valor normalizado ; IM= Indicador de medida; IMAX = Valor do indicador máximo; IMIN= Valor do indicador mínimo.

Os valores normalizados variam de 0 a 1 , representam respectivamente o pior e o melhor do ponto de vista de qualidade ambiental, independentemente das medidas absolutas usadas para cada indicador. Obviamente, estabelece-se uma relação de linearidade entre medidas de indicadores e valores de qualidade.

Alguns indicadores de degradação podem apresentar índices com valores altos, nestes casos deverá ser feita uma normalização do índice para que o resultado seja menor. Este procedimento é 
fei-to utilizando o método inverso, ou seja, subtraindo o valor obtido por 1,0 .

2 - A escala de 0 - 1 é dividida em 5 classes iguais.

3 - Índices de pressão, estado e resposta são obtidas para as diferentes funções.

$\mathrm{INp}=\mathrm{Vi} * \mathrm{Wi} / \mathrm{n}$;

Onde: $\mathrm{INp}=$ Índice de naturalidade de pressão; $\mathrm{Vi}=$ Valor normalizado (para cada indicador); $\mathrm{Wi}=$ peso do indicador; $\mathrm{n}=$ número de indicadores; $\mathrm{Wi}=1$. Sendo assim IRp (Fonte de recursos), IWp (Sumidouro) e ISSp (Suporte/Serviços) são calculados de forma análoga. $\mathrm{O}$ mesmo procedimento é usado para calcular índices de estado e resposta.

4 - índices de P, E e R, são integrados em índices de funções.

$\mathrm{IN}=(\mathrm{INp}+\mathrm{INs}+\mathrm{INr}) / 3$

Onde: $\mathrm{IN}=$ Índice de naturalidade; $\mathrm{INp}=$ Índice de naturalidade de pressão; Ins = Índice de naturalidade de sumidouro; $\mathrm{INr}=$ Índice de naturalidade de resposta.

Embora pesos iguais são considerados para índices de pressão, estado e resposta, poderão ser usados pesos diferentes.

5 - O índice de qualidade ambiental final (EQ) é o resultado da agregação de índices de naturalidade (IN), índice de fonte de recursos (IR), índice de sumidouro (IW) e índice de suporte/serviços (ISS). $\mathrm{EQ}=(\mathrm{IN}+\mathrm{IR}+\mathrm{IW}+\mathrm{ISS}) / 4$

Conforme a necessidade e complexidade dos ambientes, permite-se o uso de pesos diferentes para os componentes individuais de cada índice. Deve-se destacar que as dificuldades em atribuir pesos para os componentes individuais de cada indice, tiveram várias propostas e aproximações (Bal-key, 1968, Edwards \& Newman, 1982), ressaltando sempre uma certa margem para subjetividade.

\section{Exemplos da aplicabilidade do método}

Pretendendo oferecer uma visão mais a-brangente desta proposta metodológica com resul-tados práticos, são apresentados de forma sintética os resultados obtidos para o grau de naturalidade de ambientes em cinco áreas de estudo em regiões geo-gráficas distintas contextualizadas em suas particu-laridades locais. São elas: cidade de Rio Branco AC (Brasil), Tabernas Almería (Espanha), Rio Quarto Córdoba (Argentina), Bacia dos Córrego Carnaval e Martín (parte dos municípios de La Plata e Ensenada na Argentina) e na Reserva da Biosfera Laguna de Pozuelos (noroeste da Argentina).

$O$ cálculo do índice de naturalidade consti-tui-se no primeiro passo metodológico para avali-ação da qualidade ambiental. Para a obtenção do índice de qualidade ambiental (EQ) deve ser feita a média através da somatória do índice de naturalidade (IN) com os valores calculados para os índices fonte de recursos (IR), sumidouro (IW) e suporte/serviços (ISS).

\subsection{Rio Branco AC, Brasil}

Na cidade de Rio Branco-Acre, Brasil (Figura 3), a expansão urbana intensificada, a partir da década de 70 , combinada à falta de planejamento, resultou em diversos assentamentos em áreas de riscos geomorfológicos. Esta ocupação urbana caótica tem se produzido em áreas de baixo gradiente altimétrico, ao longo de planícies de inundação e áreas sujeitas à saturação dos níveis freáticos.

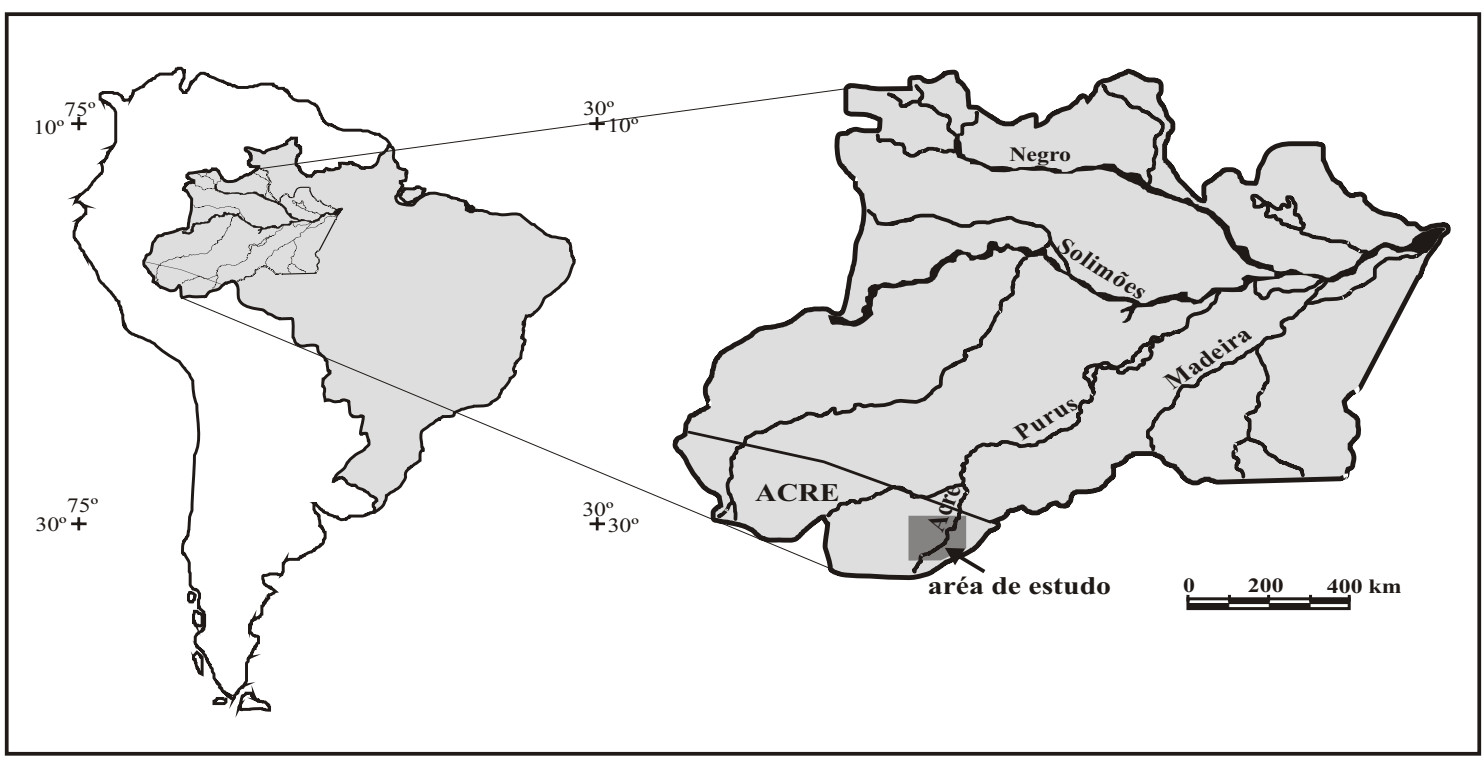

Figura 3. Localização da área de estudo. 


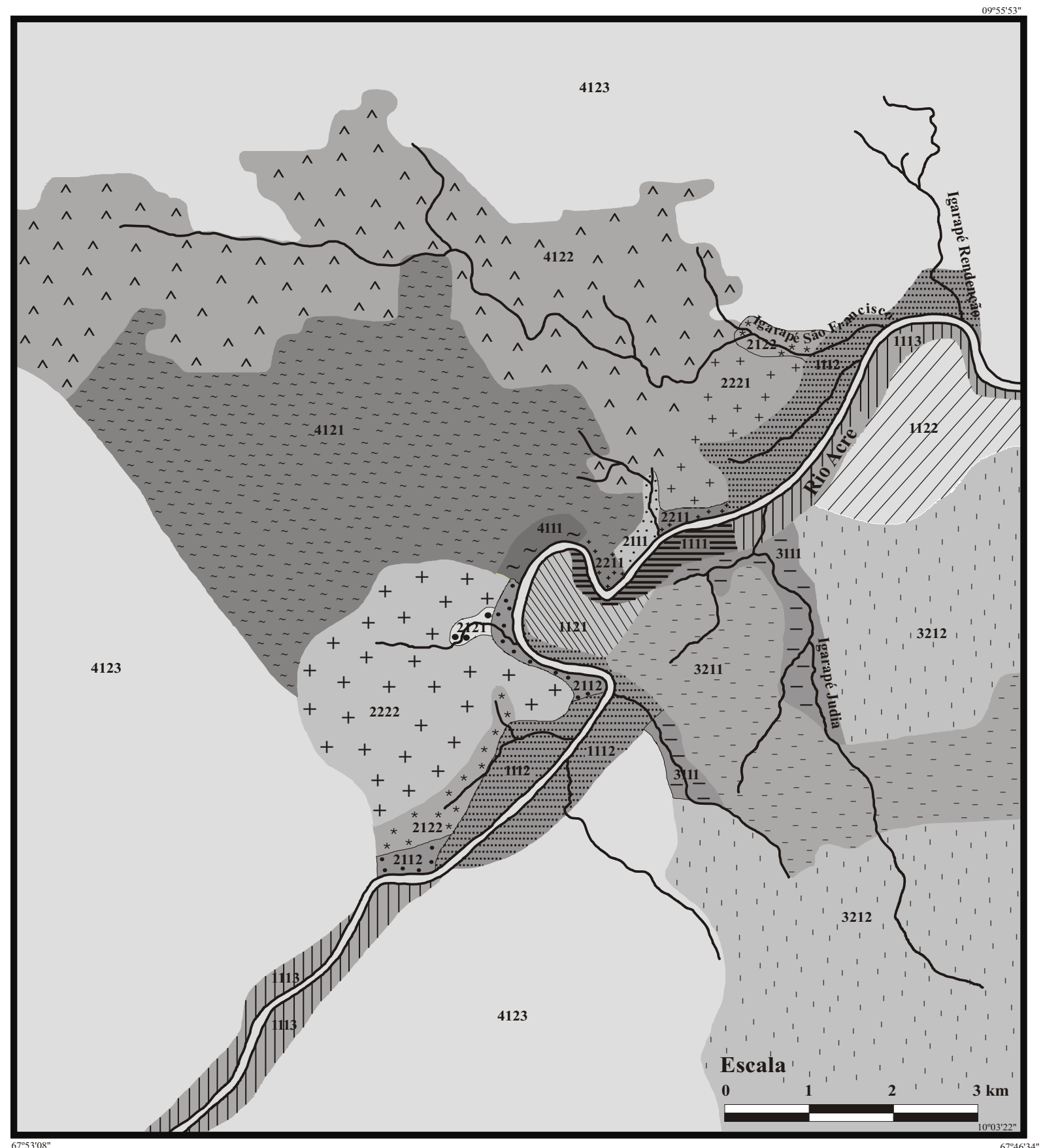

Figura 4.1 - Mapa de Unidades Ambientais Integradas de Rio Branco, Acre - Brasil.

As Unidades Ambientais Integradas (Figuras $4.1 \mathrm{e}$ 4.2) foram definidas em função de aspectos físiconaturais e político-administrativos. Os produ-tos consistiram na elaboração dos mapas: geomorfológico, solos, áreas de riscos de inundação e movimentos de massa associados (limitações geotécnicas) e de uso e ocupação do solo urbano.

Os indicadores utilizados na análise das Unidades Ambientais Integradas constam na Tabela 2.

Os resultados obtidos para as distintas unidades mostram índices de naturalidade com valores entre 0,01 e 0,63 . Os valores menores correspondem a unidades com maior densidade urbana, especialmente aquelas caracterizadas por um elevado risco de inundação e movimentos de massa. As unidades que apresentam índices de naturalidade com valores próximos de 0,63 correspondem a áreas localizadas nos setores periurbanos da cidade, onde a ação antrópica é menos expressiva.

\subsection{Tabernas, Almería - Espanha}

A área de estudo (Tabernas - Almería) situa-se no sudeste da Espanha (Figura 5), numa 


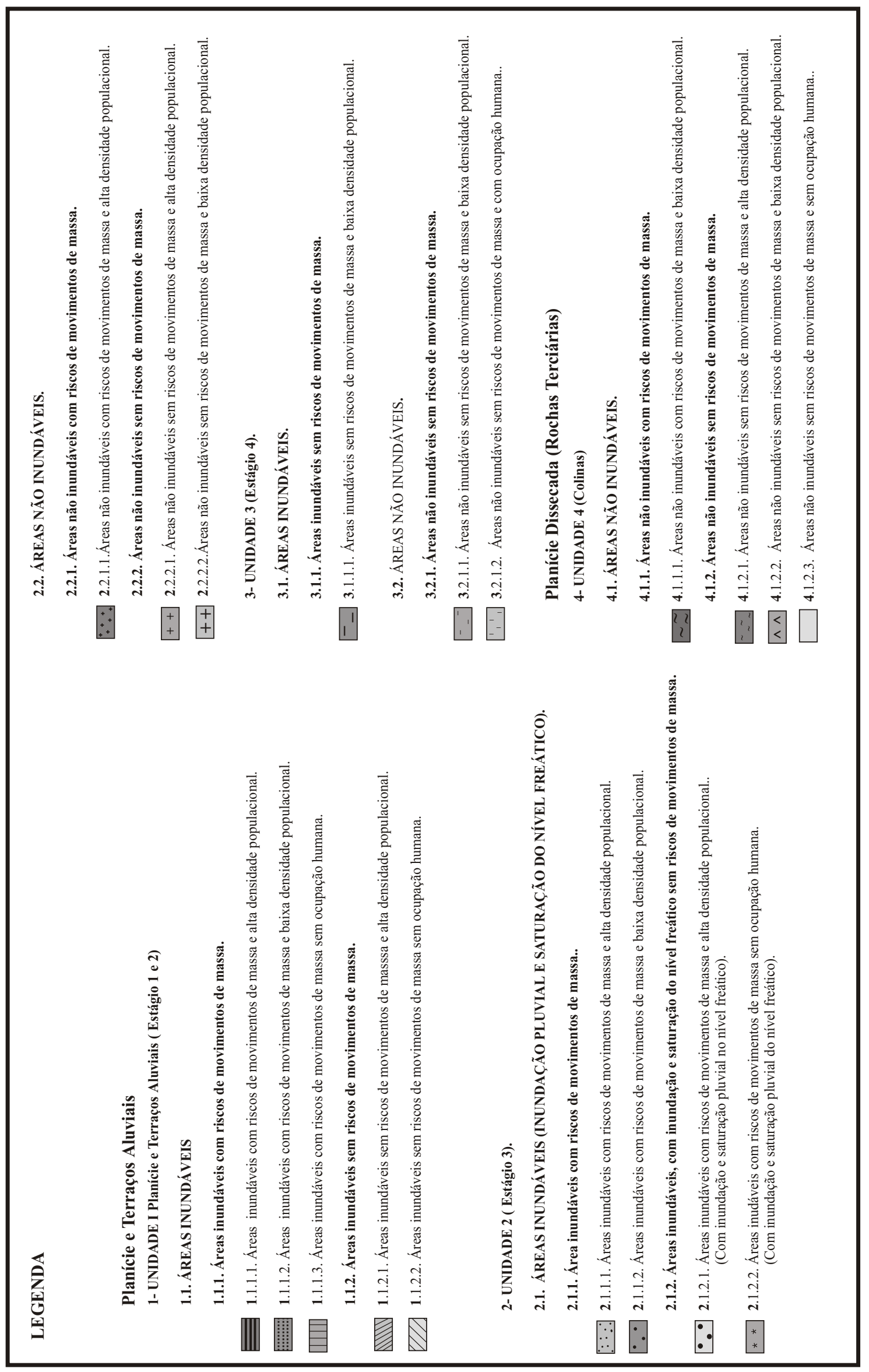

Figura 4.2. Referência da figura 4 (Mapa de Unidades Ambientais Integradas) 


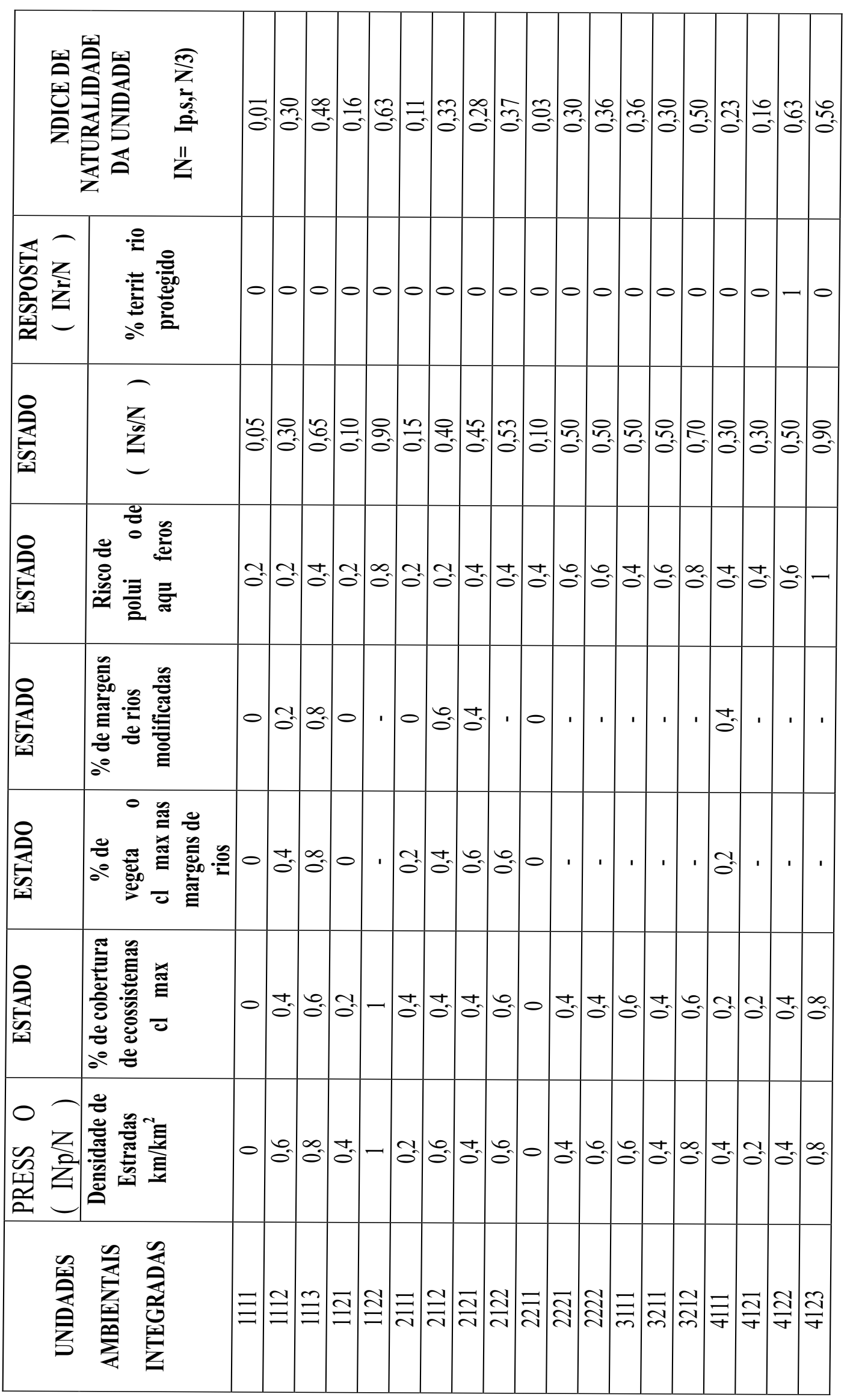



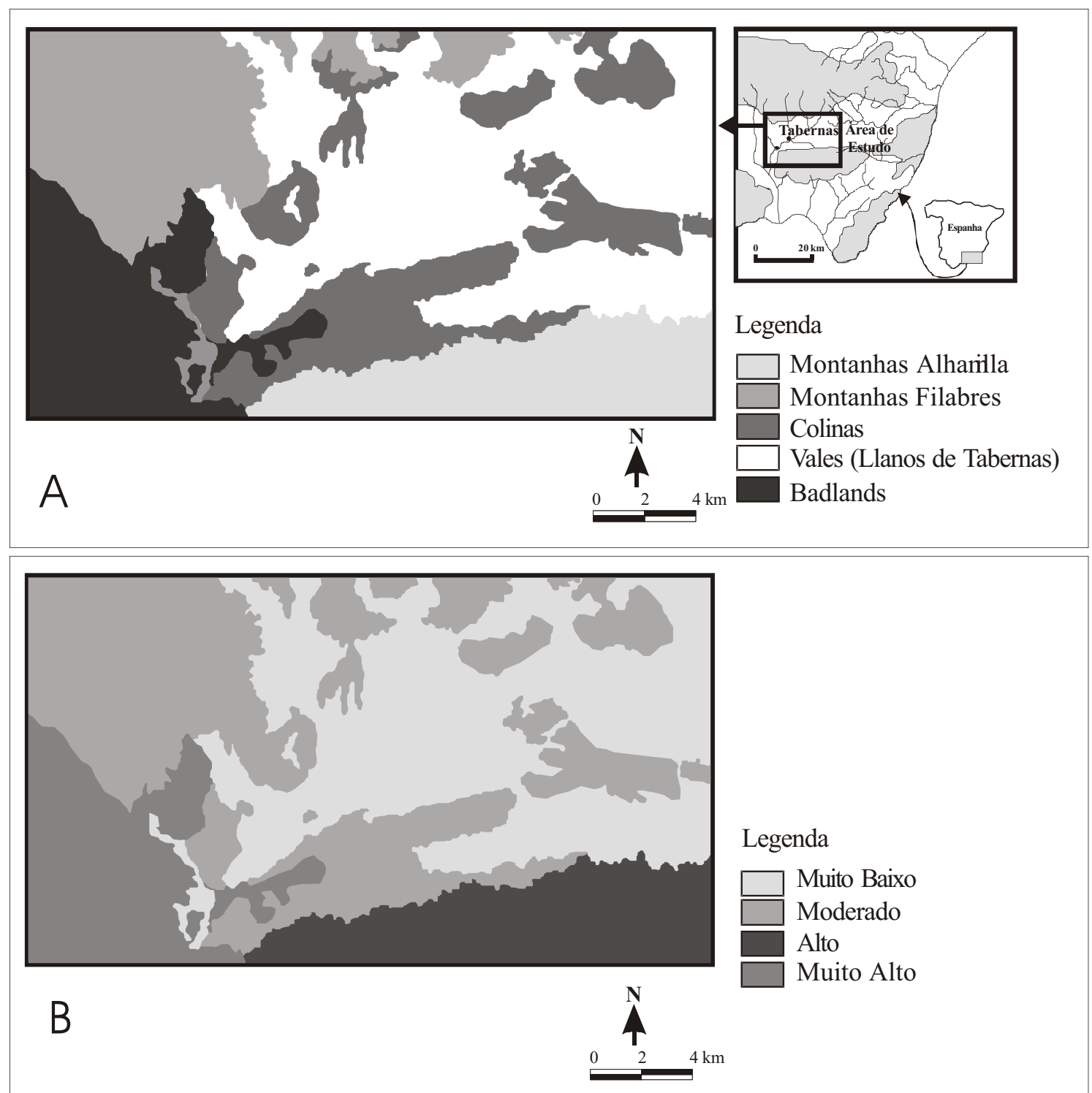

Figura 5 (a): Localização e ambinete naturais de tabernas, Almeida-Espanha. (B)Ambientes de naturalidade de tabernas, Almeria-Espanha.

área mediterrânea de alto risco de desertificação. Ativida-des humanas como agricultura, pecuária, mineração, industria e turismo aumentam este risco, ameaçando a qualidade ambiental em Tabernas, já que o poten-cial de uso da terra é inerentemente baixo devido à sua aridez.

Nesta fase preliminar de avaliação do grau de naturalidade, $\mathrm{o}$ aspecto que realmente interessa é a qualidade ambiental. Grandes unidades ambientais integradas (Ambientes Naturais), foram identificadas tendo como base as unidades de avaliação climáti-cas, morfoestruturais e topográficas conforme figura $5 \mathrm{~b}$. Na tabela 3 estão discriminados os indicadores selecionados para avaliação, segundo a representati-vidade de cada qual em medir o grau de naturalidade e a disponibilidade da aplicação dos dados.

A naturalidade foi calculada usando a ex- pressão descrita na seção metodologia. O valor mais alto do índice de naturalidade corresponde ao ambi-ente de badlands que faz parte do Deserto de Tabernas, localizado em zona rural inóspita, cuja única presença humana se refere a uma indústria ci-nematográfica. O grau de naturalidade mais baixo corresponde ao ambiente de vales (Llanos de Taber-na), cuja área apresentase com maior potencial para desenvolvimento de atividades humanas.

Ao classificar a naturalidade dos ambientes em cinco classes (muito alto, alto, moderado, baixo e muito baixo), de acordo com os valores máximo e mínimo, definiu-se para os indicadores muito alto e alto, os badlands e as montanhas de Alhamilla res-pectivamente (Tabela 3). Tal fato coincide com a preocupação social e de autoridades ambientais (o Governo 


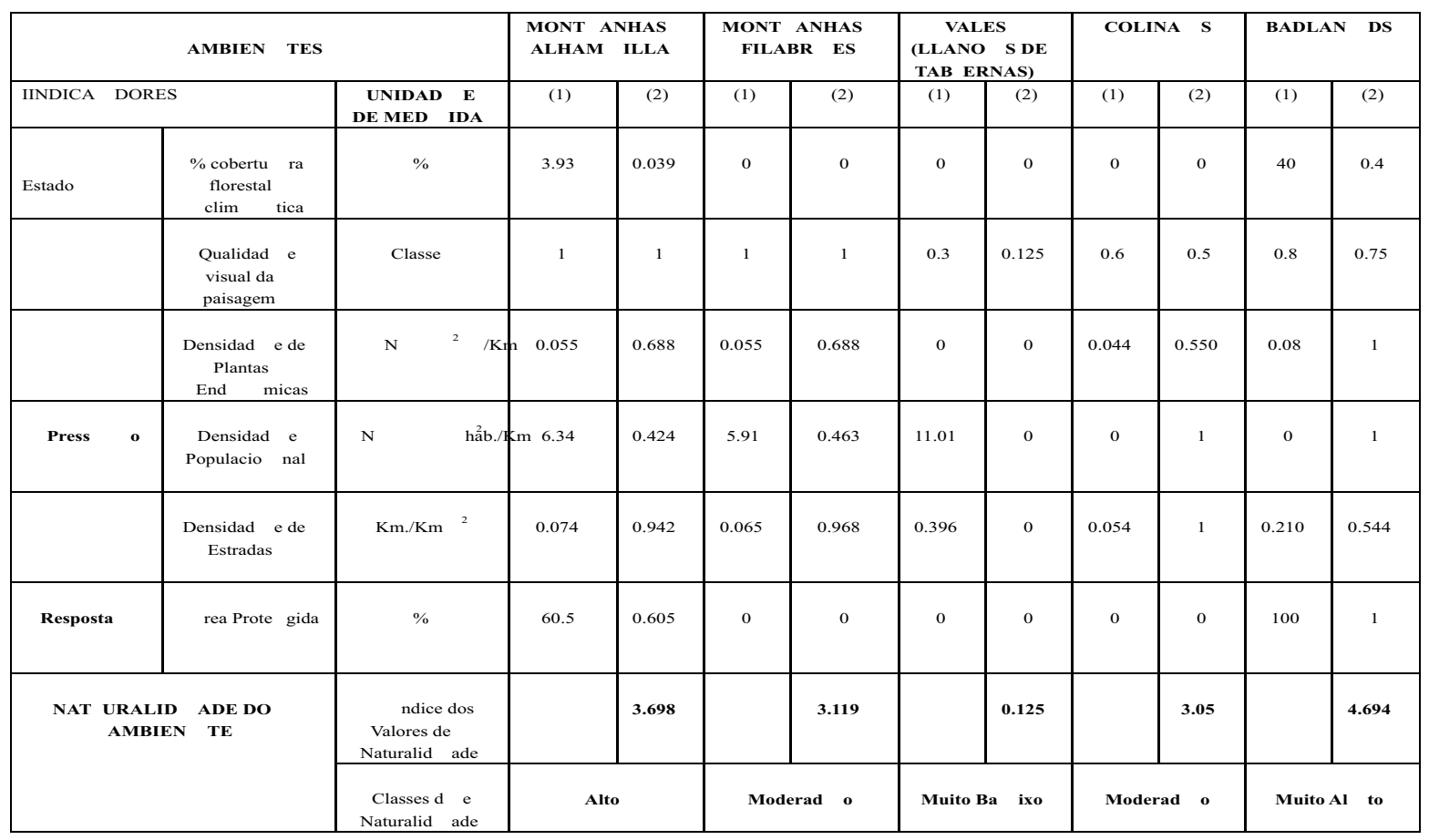

Regional de Junta de Andalucía), que de-clarou, recentemente, ambos os ambientes como par-ques naturais. Há, atualmente, uma proposta em de-clarar o deserto de Tabernas como parque nacional objetivando a proteção de sua naturalidade e de possíveis impactos de desenvolvimento de uma infraestrutura ligada a indústria cinematográfica.

\subsection{Rio Cuarto, Córdoba - Argentina}

A área de estudo se encontra na região central da Argentina, caracteriza-se como uma extensa planície totalmente antropizada, onde os principais problemas de qualidade ambiental estão ligados às umdanças de uso da terra, isto é, de uma atividade pecuária para agropecuária. A área foi selecionada com base na diversidade de ambientes naturais, estabelecendo-se assim Unidades Ambientais Integradas (Figura 6) a partir da interação dos mapas geomorfo-lógicos, solos, qualidade e disponibilidade de água e uso da terra.

$\mathrm{O}$ indicador referido às modificações das margens dos rios permite contabilizar outras modificações antrópicas distintas além da eliminação da vegetação clímax. Nas várias unidades não se avali-ou a quantidade de nitrato nos cursos d’água, nem a alteração das margens dos cursos, pois não havia cursos d'água na unidade ou talvez na época de avaliação estavam secos. O índice de naturalidade foi obtido para dezoito Unidades Ambientais Integradas utilizando a equação descrita no tópico da estrutura metodológica. Para a análise inicial utilizou-se uma expressão de um peso igual para cada indicador. Os resultados obtidos constam na tabela 4 .

Como se observa na tabela mencionada, o valor do índice de naturalidade varia de 0,17 na área urbana de San Basilio e 0,46 para a maioria das á-reas rurais. Os índices assinalam claramente o grau de alteração da naturalidade que está vinculada a uma perda total da vegetação clímax e um desapare-cimento da fauna de vertebrados que tem migrado para áreas de menores atividades antrópicas. $\mathrm{O}$ indicador de resposta é nulo já que não há território protegido ou submetido a restrições de uso. As áreas rurais, de forma geral, tem índices de naturalidade mais altos $(0,39$ a $0,46)$ uma vez que a água superficial e subterrânea não apresentam perdas de naturalidade e a pressão é relativamente baixa. As unidades urbanas mostram valores mais baixos $(0,17$ a 0,39$)$ pois são afetadas pela presença de riscos à qualidade da água subterrânea, onde a pressão é mais alta.

\subsection{Bacia do Córrego Carnaval Martín parte dos municípios de La Plata e Ensenada Argentina}

A área de estudo está constituída pela bacia dos córregos Carnaval e Martín, abrangendo uma superfície de 123,63 km incluindo parte dos muni-cípios de La Plata e Enseada (municípios satélites da Capital Federal Buenos Aires). Neste setor se desenvolvem atividades diversas que têm conduzido conflitos de uso da terra e degradação dos recursos naturais.

Conforme a paisagem e sua gênese, se reconheceu quatro Unidades Ambientais Integradas (Figura 7). Os interflúvios, tanto principais como se-cundários, apresentam formas planas e plano con-vexas e estão constituídos principalmente por sedi-mentos loéssicos (silto-argilosos). As planícies de i- 


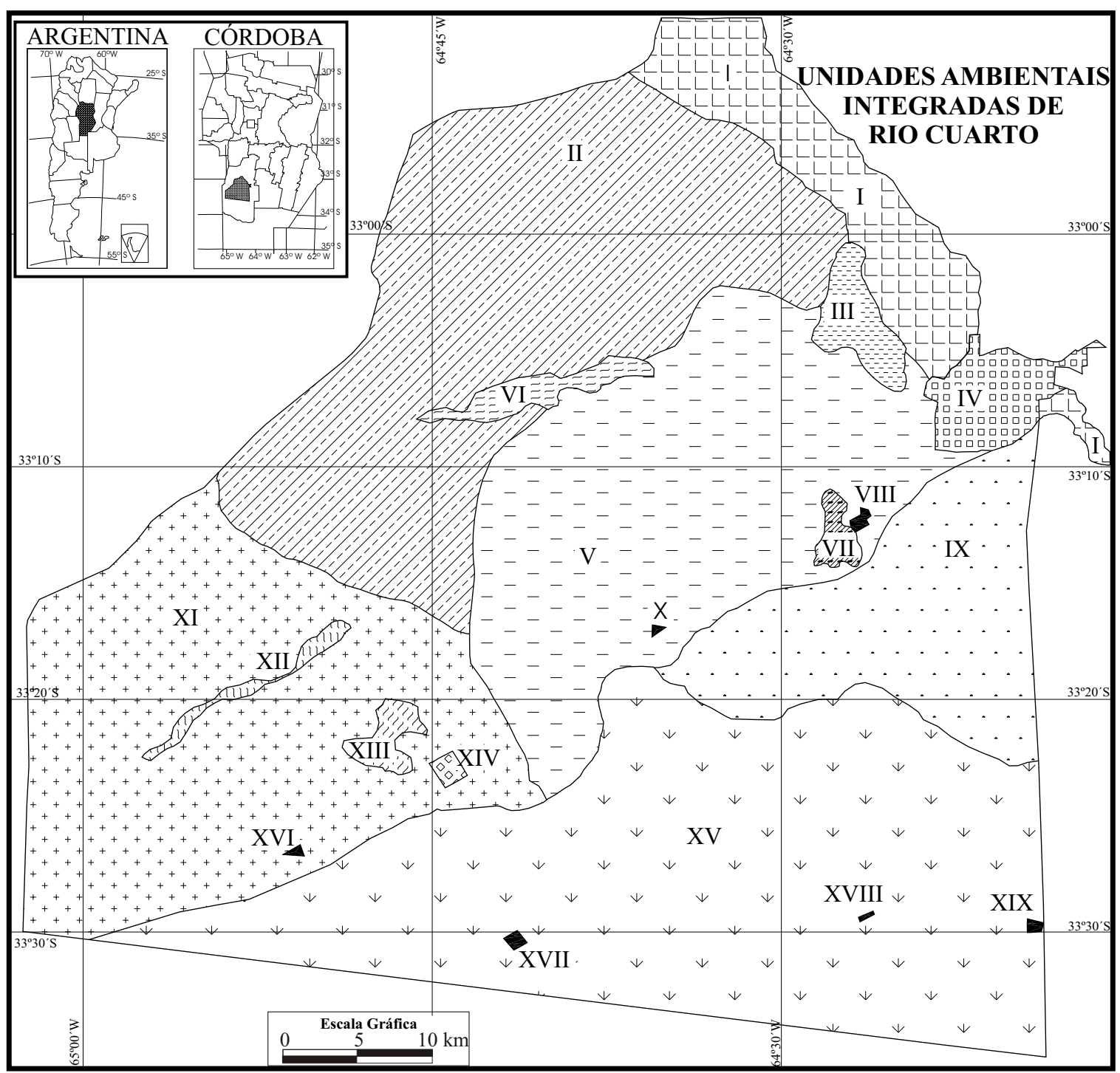

nundação dos cursos de água principais e secundários tem extensões laterais que não superam os 100 metros e estão constituídos por siltes argilosos e arenosos. A Planície Costeira do estuário do Rio da Plata é uma área plano-côncava pobremente drenada, de litologias muito heterogênea com predomínio de materiais argilosos. A Planície Aluvial ocupa u-ma franja plana, paralela à costa atual, influenciada pela ação das marés apresentando alternância de areias, argilas e material orgânico.

Os índices calculados (Tabela 5) têm re- lação razoável com uma apreciação intuitiva da situação ambiental no que se refere à naturalidade.

$\mathrm{O}$ índice mais alto corresponde à unidade Planície Aluvial, com uma importante superfície o-cupada por uma reserva natural. Entretanto, seu grau de naturalidade não chega a categoria máxima (5) devido a presença de infraestruturas. $O$ alto índice desta unidade não elevou significativamente o índice de naturalidade da área de estudo devido a sua escassa representação areal. As demais unidades tem índices médios e baixos, tendo sido 
Tabela 4: Indicadores e Índices de naturalidade das Unidades Ambientais do Rio Cuarto, Córdoba - Argentina.

\begin{tabular}{|c|c|c|c|c|c|c|c|c|c|c|c|c|c|c|c|c|c|c|c|}
\hline & \multicolumn{19}{|c|}{ UNIDADES AMBIENTAIS INTEGRADAS } \\
\hline $\begin{array}{l}\text { INDICADORES DE } \\
\text { NATURALIDADE }\end{array}$ & I & II & III & IV & $\mathbf{v}$ & VI & VII & VIII & IX & $\mathbf{x}$ & $\mathbf{X I}$ & XII & XIII & XIV & $\mathbf{X V}$ & XVI & XVII & XVIII & XIX \\
\hline PREMREQS O & & & & & & & & & & & & & & & & & & & \\
\hline $\begin{array}{c}\text { Densidade de Estradas } \\
\mathrm{Km} / \mathrm{Km}^{2}\end{array}$ & 1 & 1 & 1 & .5 & 1 & 1 & 1 & .75 & 1 & .5 & 1 & 1 & 1 & 1 & 1 & .75 & .75 & 1 & .5 \\
\hline ESTADO & & & & & & & & & & & & & & & & & & & \\
\hline \%o Ecossistemas Clímax & 0 & 0 & 0 & 0 & 0 & 0 & 0 & 0 & 0 & 0 & 0 & 0 & 0 & 0 & 0 & 0 & 0 & 0 & 0 \\
\hline 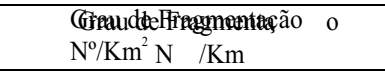 & 0 & 0 & 0 & 0 & 0 & 0 & 0 & 0 & 0 & 0 & 0 & 0 & 0 & 0 & 0 & 0 & 0 & 0 & 0 \\
\hline $\begin{array}{l}\% \text { veg. Climax em margens de rios } \\
\text { margens de rios }\end{array}$ & 0 & 0 & 0 & 0 & 0 & 0 & 0 & 0 & 0 & 0 & 0 & 0 & 0 & 0 & 0 & 0 & 0 & 0 & 0 \\
\hline $\begin{array}{l}\text { \%\%mbadifificaçõesshntss margens de ri } \\
\text { margens de rios }\end{array}$ & 1 & 1 & 1 & .75 & 1 & 0 & 1 & 1 & 1 & \# & .75 & 1 & 1 & .5 & .5 & $\#$ & 0 & 1 & \# \\
\hline $\begin{array}{l}\text { Nitratitrato em cursos d gua } \\
\text { Nursosd agua }\end{array}$ & 1 & 1 & \# & .75 & 1 & 1 & .5 & 1 & 1 & \# & 1 & 1 & \# & \# & 1 & $\#$ & $\#$ & \# & \# \\
\hline $\begin{array}{l}\text { RRisce delepplolingnõo deo de aqu fero } \\
\text { aquíferos }\end{array}$ & .75 & .75 & .25 & 0 & .75 & .25 & 1 & .5 & .75 & .5 & .75 & .75 & 1 & 0 & .75 & 0 & .75 & 0 & 0 \\
\hline 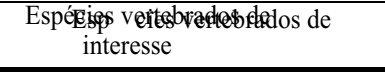 & 0 & 0 & 0 & 0 & 0 & 0 & 0 & 0 & 0 & 0 & 0 & 0 & 0 & 0 & 0 & 0 & 0 & 0 & 0 \\
\hline RESPOSTA & & & & & & & & & & & & & & & & & & & \\
\hline 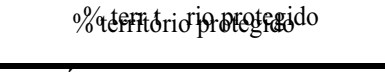 & 0 & 0 & 0 & 0 & 0 & 0 & 0 & 0 & 0 & 0 & 0 & 0 & 0 & 0 & 0 & 0 & 0 & 0 & 0 \\
\hline İNDICE NDICE & .46 & .46 & .40 & .24 & .46 & .39 & .45 & .37 & .46 & .20 & .45 & .46 & .44 & .36 & .44 & .25 & .29 & .39 & .17 \\
\hline
\end{tabular}

Tabela 5: Índices e grau de naturalidade da bacia dos Córregos Carnaval e Martin.

\begin{tabular}{|c|c|c|c|}
\hline Unidades Ambientais Integradas & $\begin{array}{l}\text { Supperficicie } \\
\left(\mathrm{km}^{2}\right)\end{array}$ & $\begin{array}{c}\text { Ìndindide de } \\
\text { Naturalidade }\end{array}$ & $\begin{array}{c}\text { Grau de } \\
\text { Naturalidade }\end{array}$ \\
\hline Interflúviaंøs & 73,62 & 0,41 & 3 MaAlio dio \\
\hline PlaníciesesedinHnadaqão & 8,50 & 0,37 & 2 Baixo \\
\hline Planícieieosnsiteira & 37,81 & 0,47 & 3 Mádiodio \\
\hline PPlańciecidualiavial & 3,72 & 0,67 & 4 Alto \\
\hline Árearat botal & 123,65 & 0,43 & 3 MAtiodio \\
\hline
\end{tabular}

influenciado principalmente pela escassa presença de ecossistemas climáxicos, substituídos pelo uso agrícola e urbano, agentes ativos na contaminação dos cursos d'água.

\subsection{Reserva da Biosfera Laguna de Pozuelos Noroeste da Argentina}

A Reserva da Biosfera Laguna Pozuelos é uma bacia lacustre localizada nos altiplanos do noroeste argentino (Figura 8). A área tem uma superfície de $4.000 \mathrm{~km}^{2}$ e altitudes que variam entre $3.600 \mathrm{e}$ 4.800 metros. Esta Reserva é incluída na rede MAB da UNESCO como áreas naturais protegidas. A bacia da Laguna de Pozuelos é comparativamente para os padrões andinos, uma área densamente povoada com 0,92 hab. $/ \mathrm{km}^{2}$, embora sendo a densidade populacional muito baixa.

As subdivisões estabelecidas foram: ambientes e sub-ambientes morfodinâmicos, definidos com base em critérios fisiográficos bioclimaticos; sistemas de morfodinâmica traçados de acordo com critérios geomorfológicos de processos ativos e uni- dades morfodinâmicas definidas segundo a cobertura vegetal. Identificadas as unidades morfodinâmicas foi traçada uma área piloto de 800 $\mathrm{km}^{2}$.

Os valores máximos e mínimos foram ajus-tados numa escala que varia de 0 l 1 em diferentes unidades da bacia.

As unidades morfodinâmicas foram indivi-dualmente selecionadas. A área mais protegida é a lagoa central, ou seja, a Laguna de Pozuelos (área core da Reserva da Biosfera). Por outro lado foi selecionada uma unidade ocupada por determinação de uma pequena atividade humana onde se destaca o pastoreio intensivo (Rodeio).

Na tabela 6 estão os índices de pressão, estado e resposta para as diferentes áreas e o índice de naturalidade integrado. Pesos iguais foram consi-derados para os cálculos de pressão, estado e resposta.

Como seria esperado a naturalidade da Uni-dade Laguna de Pozuelos ficou próximo de 1. O índice de naturalidade da bacia inteira pode 


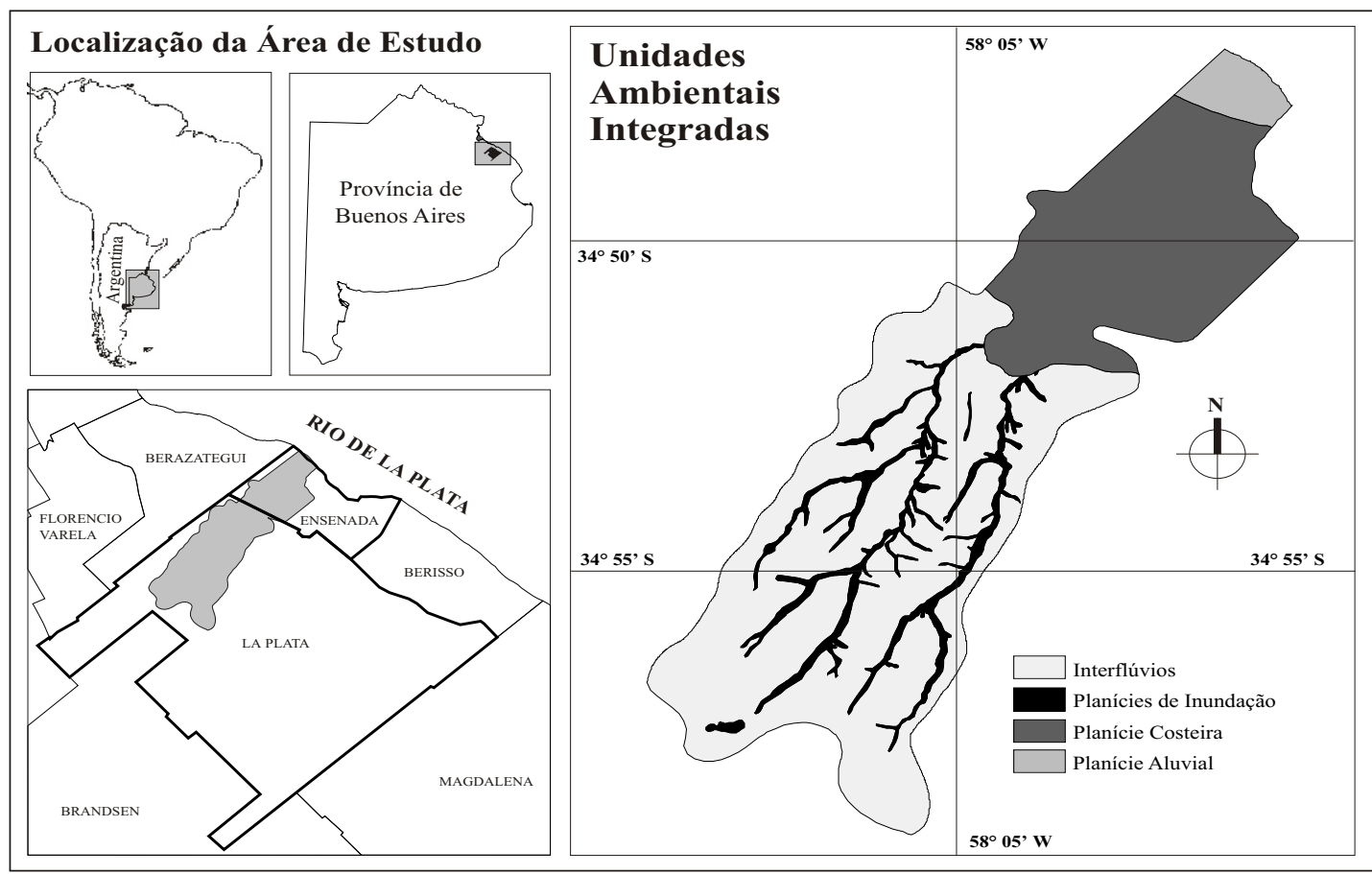

Figura 7: Localização e Unidades Ambientais Integradas da bacia dos córregos Carnaval e Martn.

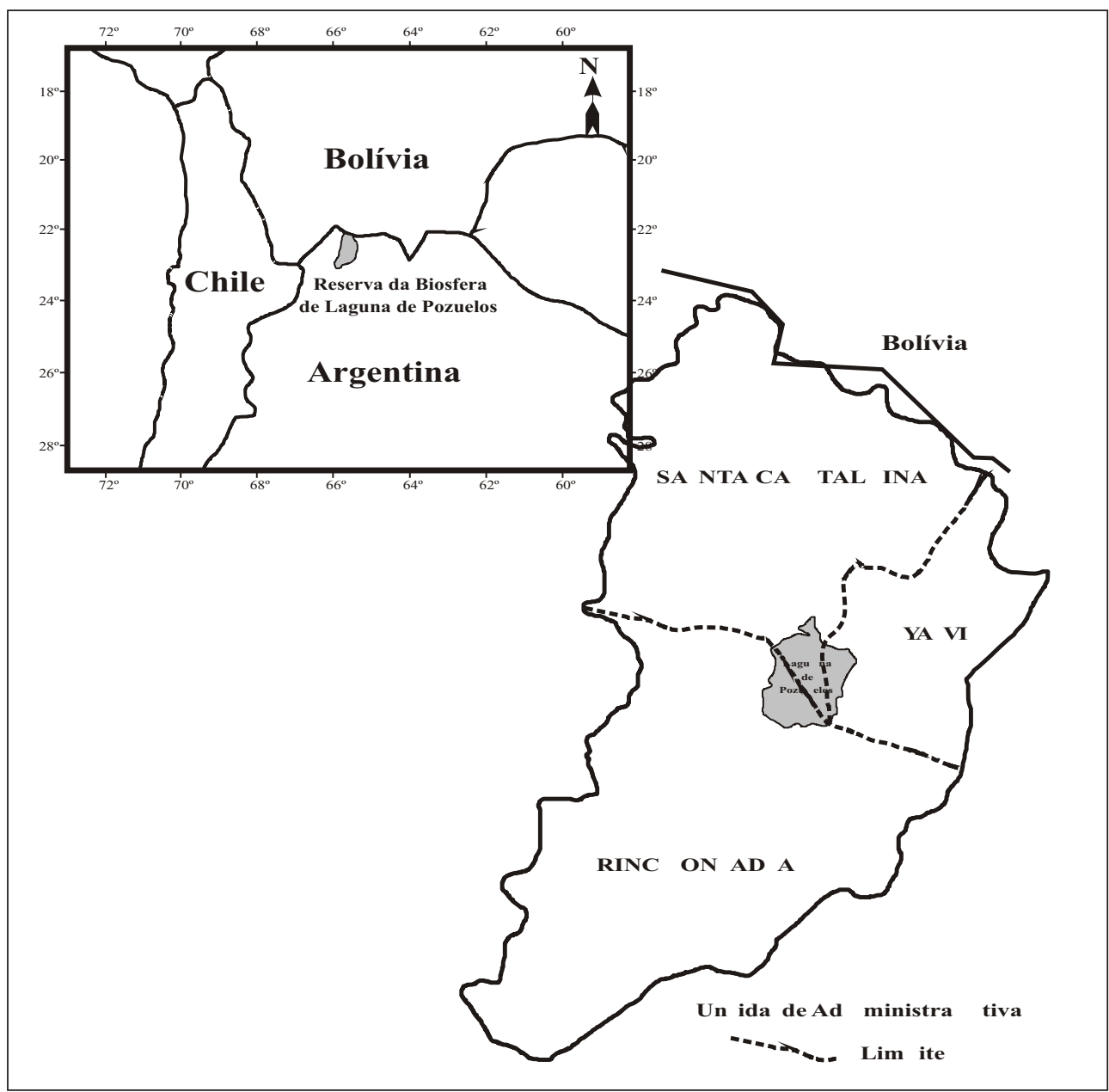

Figura 8: Reserva da Biosfera Laguna de Pozuelo: Localização e Unidades Administrativa. 
Tabela 6: Indicadores e índices de naturalidade de Laguna de Pozuelos.

\begin{tabular}{|c|c|c|c|c|c|c|}
\hline \multicolumn{2}{|c|}{ RESERV A DA BIOSFERA } & \multicolumn{3}{|c|}{$\underset{\text { Valores por }}{\text { Valores por }} \mathrm{Km}^{\mathrm{km}}$} & & \\
\hline \multirow{2}{*}{\multicolumn{2}{|c|}{$\begin{array}{cl}\text { LAGUNA DE POZUE } & \text { LOS } \\
\text { NATURALIDAD } & \mathrm{E}\end{array}$}} & & & & & \\
\hline & & Mimimo & nimoMáximo xim $\phi$ & $\begin{array}{l}\text { Valores } \\
\text { obtidos }\end{array}$ & $\begin{array}{r}\text { Valores } \\
\text { Normalisados }\end{array}$ & $(0-1)$ \\
\hline PRESSÃO O & Estradas princ ipais & 0.32 & 0 & 0.12 & 0.625 & \\
\hline \multirow{6}{*}{ ESTADO } & $\begin{array}{l}\text { Cobertula Cli máxica de xica de } \\
\text { Ecossistemas }\end{array}$ & 0 & 1 & 0.387 & 0.387 & \\
\hline & Grau de Fragm entação & 0.026 & 0 & 0.017 & 0.346 & \\
\hline & $\begin{array}{l}\text { Grau de fhteł vehção } \\
\text { margens de canais }\end{array}$ & 0.026 & 0 & 0.0002 & 0.992 & \\
\hline & 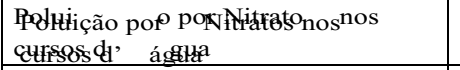 & 0.013 & 0 & 0 & 1 & \\
\hline & 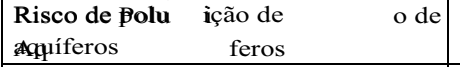 & 0.008 & 0 & 0.000006 & 0.999 & \\
\hline & $\begin{array}{l}\text { Espécies de ciefoctuedatadołede } \\
\text { Interesse }\end{array}$ & 0 & 0.026 & 0.006 & 0,23 & \\
\hline RE SPOST A & Territitório Pooprgitegidø & 0 & 0.026 & 0.026 & 1 & \\
\hline
\end{tabular}

ser con-siderado como um valor médio de referência para fazer comparações entre regiões diferentes, especial-mente, áreas protegidas.

\section{Considerações Finais}

O Projeto RELESA/ELANEM destaca-se como uma nova proposta metodológica destinada à aplicação de indicadores quantitativos e índices de a-valiação da qualidade ambiental. Os trabalhos estão em desenvolvimento em dez centros de pesquisa, em oito países da Europa e da América Latina, abran-gendo um amplo conjunto de condições ambientais naturais e humanas.

A diversidade ambiental das áreas estudadas dá ênfase à proposta de aplicação de indicadores quantitativos permitindo mensurar a qualidade ambi-ental desenvolvendo instrumentos e técnicas que possam aprimorar o entendimento das interações entre as atividades humanas, situação dos recursos e dos ecossistemas, conduzindo a um aperfeiçoamento nos modelos de gerenciamento dos recursos naturais.

A espacialização dos resultados se dá através da identificação, mapeamento e análise de Unidades Ambientais Integradas, as quais foram delimitadas com atributos distintos tendo como parâmetro a realidade natural e as formas de uso e ocupação de cada área. O componente geomorfológico passa a assumir uma importância fundamental na delimi-tação destas unidades.

Resultados preliminares das pesquisas reve-lam com clareza a validade do método, como de-monstram os cálculos realizados para o grau de natu-ralidade do ambiente em distintas áreas, aqui apre-sentada.

\section{Bibliografia}

Balkey, N.C. (1968). The Delphi method; an experimental study of group opinion. Rand Memorandum 5888. P. R. Rand Corporation, Santa Monica, Ca.
Cendrero, A., Francés, E. \& Díaz De Terán, J. R (1992). Geoenvironmental units as a basis for assessment, regulation and management of the earth's surface. IN: CENDRERO, A., LUTTIG, G. \& WOLFF, F. C. (eds). Planning the use of the Earth's surface. Springer-Verlag, N.York: 199-234.

Edwards, W. \& Newman, J.R. (1982). Multiattribute evaluation, Sage, Beverly Hills, Ca.

FAO. (1997) Land Quality indicators and their use in sustainable agriculture and rural development. FAO Land and Water Bulletin, 5.

Jiménez-Beltrán, D. (2000). Los indicadores ambientales como instrumento al servicio de la política ambiental y para el desarrollo sostenible. IN: Estadística y medio ambiente. Instituto de Estadística de Andalucía, Sevilla, pp 11-27.

Mortensen, L.F. (1997). The driving force-stateresponse framework used by the CSD. IN: MOLDAN, B. \& BILLHARZ, S. (eds). Sustainability indicators. Wiley, ChichesterN. York: 47-53.

OECD. (1993). Core set of indicators for environmental performance reviews. OECD, Paris.

OECE. (1994). Environmental indicators. OCDE, Paris.

SCOPE (1995). Environmental indicators; a systema-tic approach to measuring and reporting on the environment in the context of sustainable development. IN: GOUZEE,N. MAZIJN, N \& BILLHARZ, S. (Eds) Indicators of sustainable development for decision-making, Eds. Federal Planning Office, Bruselas: $25 \mathrm{p}$

UNDP. (1996). Human development report. Oxford University Press, Oxford.

UNDP-UNDPCSD (1995). The role of indicators in decision-making. IN: GOUZEE,N.

Mazijn, N \& Billharz, S. (Eds) Indicators of sustainable development for decision-making. Federal Planning Office, Bruselas: $17 \mathrm{p}$. 